\title{
Roleplaying as tool for helping LAs sense-make about inequitable team dynamics
}

Hannah Sabo, ${ }^{1}$ Jennifer Radoff, ${ }^{2}$ Andrew Elby, ${ }^{1}$ Ayush Gupta, ${ }^{2}$ and Chandra Turpen ${ }^{2}$

1 †Department of Teaching \& Learning, Policy \& Leadership, University of Maryland, College Park, MD 20742

${ }^{2}$ Department of Physics, University of Maryland, College Park, 082 Regents Dr., College Park, MD 20742, USA

Learning Assistants (LAs) are peer-educators in undergraduate courses who take a pedagogy seminar concurrently with teaching. In our Learning Assistant pedagogy course, we engaged LAs in roleplaying interactions between a quiet student, an overbearing student, and an LA. Afterwards, the whole class discussed the roleplay activity. Drawing on tools from discourse analysis, we attend to how roleplay actors navigate speech, turns-of-talk, and physical orientation. We show that the LA playing the role of the overbearing student, drawing on his emotionally-charged embodied experience in the roleplay, articulated insights about how the coupling of linguistic, metalinguistic, and emotional qualities in those interactions affected the power dynamics and emotions embedded in interactions.

\section{INTRODUCTION}

The LA model prepares undergraduates to teach their peers [1]. In the pedagogy seminar, the LAs engage in activities such as discussing readings, watching videos of teaching, and reflecting on their own experiences as facilitators of small-group work. In addition, LA pedagogy classes sometimes use roleplays to practice teaching.

$\mathrm{K}-12$ teacher educators have long used roleplays, where one pre-service teacher plays the part of a teacher and other pre-service teachers pretend they're students in an improvised classroom "scene," to help prepare future teachers for the rough and tumble of classroom interactions. Research on pre-service K-12 teachers gives us reason for optimism about the benefits of roleplays. Roleplays increase the self-efficacy of pre-service teachers [2], help them become more self-aware about inclusive teaching practices for student with special needs [3], and improve targeted communications skills [4]. Indeed, leaders of the "practicebased" teacher education movement advocate inclusion of roleplays with feedback [5].

More recently, a small body of research has suggested similar benefits of roleplays in LA pedagogy courses. Cook \& Von Korff found that roleplays help peer educators practice ways to draw out students' reasoning and engender student collaboration [6]. And our colleagues, studying the same LA pedagogy course discussed in this paper, show that roleplays can make instructors aware of the emotional stakes students face [7].

In both settings (K-12 and LA seminars), the pedagogy course instructor typically focuses attention on the "teacher" in the roleplay - how they attended to "student" thinking, what moves the "teacher" made, what other moves might be possible, and so on. Similarly, research on the efficacy of roleplays in teacher education usually focuses on their efficacy for helping the pre-service teacher become better at noticing and responding to student ideas and engaging in other effective teaching practices [2] [3] [4] [5] [6].

In this paper, we take a different tack, both as pedagogy course instructors and as researchers. In the LA pedagogy course post-roleplay discussion, part of the conversation focused on the "student" experience. And in our description and analysis below of that roleplaying scene, we focus as much on the emotional and power dynamics as on the cognitive aspects of the interactions. From this analysis, we argue that role-plays are helpful not just for practicing and reflecting upon teaching techniques, but also for helping LAs feel their students' perspectives in ways that increase their understanding of the power dynamics and emotions prevalent in small-group interactions.

In this paper, we show that by enacting, observing, and discussing roleplays, LAs can develop deep embodied knowledge of power dynamics and emotions embedded in interactions, partly by making visible the coupling of linguistic, metalinguistic, and emotional qualities in those interactions.

\section{CONTEXT \& METHODS}

The learning assistants (LAs) act as peer-educators in a first-year project-based introduction to engineering design course required of all engineering majors at a large MidAtlantic public university. Within each 40 -student section, 8student teams create an autonomous robot that navigates on sandy terrain and accomplishes missions such as locating copper or steel debris, identifying the material, and picking it up. LAs spend 10-12 contact hours per week with their students.

In fall of 2016, LAs teaching an introductory engineering design course were concurrently enrolled in a 3-credit LA pedagogy seminar designed to help LAs support their students in engineering design thinking as well as equitable teamwork. (Authors Gupta \& Turpen taught the seminar course.) See Quan et. al. [8] for a description of the pedagogy seminar. To help LAs notice and respond to concrete teamwork troubles that arose in their sections, we engaged them in activities such as discussing successes and challenges of teaching, reading and discussing relevant articles, roleplaying specific interactions between LAs and design teams, writing descriptions of scenarios that arose in their students' teams, brainstorming instructional moves in response to those scenarios, and imagining students' 
reactions to those moves. This paper focuses on the roleplay activity.

\section{A. Description of the Roleplay}

Midway through the semester, we asked the LAs to discuss teaching challenges they had encountered with their students. The following week, the instructors combined two of the challenges into a roleplay prompt:

Some members of the group are being overbearing. Some students, who are quieter, are overshadowed by other group members. (Note: Based on your experiences in [engineering design course], feel free to create your own local context around these issues for the roleplay.)

(Worksheet Prompt, 10/18/16).

Three LAs performed the roleplay. "Molly" played a quiet student with tractable ideas. "Anthony", cast as the overbearing student, typically ignored these ideas in favor of pursuing his own less plausible ideas. "Christian," referred to below as LA-C, acted as the LA who intervened in Molly and Anthony's problematic dynamics. The actors created the local context around the scene: Anthony will push his idea of using a magnet to pick up the copper debris, Molly will challenge that copper is not magnetic, but Anthony will not listen. Anthony, Molly, and Christian created the general flow of the roleplay, but improvised as the roleplay unfolded. The other LAs in the seminar observed the roleplay. Afterward, all the LAs discussed the instructor moves they noticed during the roleplay. One of the actors reflected on the impact of the LA's moves.

\section{B. Methodology}

The first two authors transcribed the roleplay and the enusing whole-class discussion. Then, as a group, the authors watched the video, focusing on how the roleplay students responded to each other and interacted with LA-C. We were interested in the affordances of the roleplay for building LAs' knowledge about interactions among teammates and corresponding instructional moves. By "knowledge" we mean both explicit knowledge they might share in verbal utterances and embodied knowledge that might be encoded in their bodily actions [9]. We were also interested in how LAs (roleplayers and observers) attended to the dynamics of power and positionality among the characters in the roleplay. As such, for the roleplay itself, we analyzed both speech and gesture. We drew on tools from discourse analysis [10] to attend to how different actors took turns of talk, got interrupted or were deferred to; whose suggestions were attended to, who was oriented to as an arbiter of potential future action, as well as non-verbal markers such as physical posture, gesture, gaze, and bodily orientations that have consequences for how participants in talk are positioned. For the analysis of the de-brief conversation, we attended mostly to the substance of the utterances (observing LAs and roleplaying LAs). Sabo produced analytical memos of the roleplay and ensuing class discussion. Here, we provide a detailed description and analysis of the roleplay and focus on Anthony's reflection during the discussion.

\section{ANALYSIS}

\section{A. The Roleplay}

The roleplay opens with Anthony and Molly discussing one of Anthony's design ideas for their over-sand vehicle (OSV). The OSV's mission is to navigate to the debris, pick it up, and return to its starting position. Anthony suggests that they equip their OSV with a magnet to pick up the material. Molly is quietly skeptical of this idea; she says that she does not think the material is magnetic. Anthony insists that because the material is metal, it will be fine.

LA-C walks up to Molly and Anthony and asks if they are talking about their design ideas. LA-C starts out with both of his hands on his hips, inviting conversation from both Anthony and Molly. Anthony quickly shares his idea. LA-C asks Anthony questions about his design, questions similar to the ones Molly raised, he makes space for Molly's ideas by asking for her thoughts on Anthony's idea. Before Molly can explain why she does not think the magnet will work, Anthony interrupts her and asks "Why?" then elaborates further on his idea. Anthony replicates the problematic dynamic; his speech and actions are evidence of "embodied knowledge" about inequitable dominance in interactions. LA-C interrupts this interruption and asks Molly "Yeah, so why isn't the magnet gonna work?"; while asking this

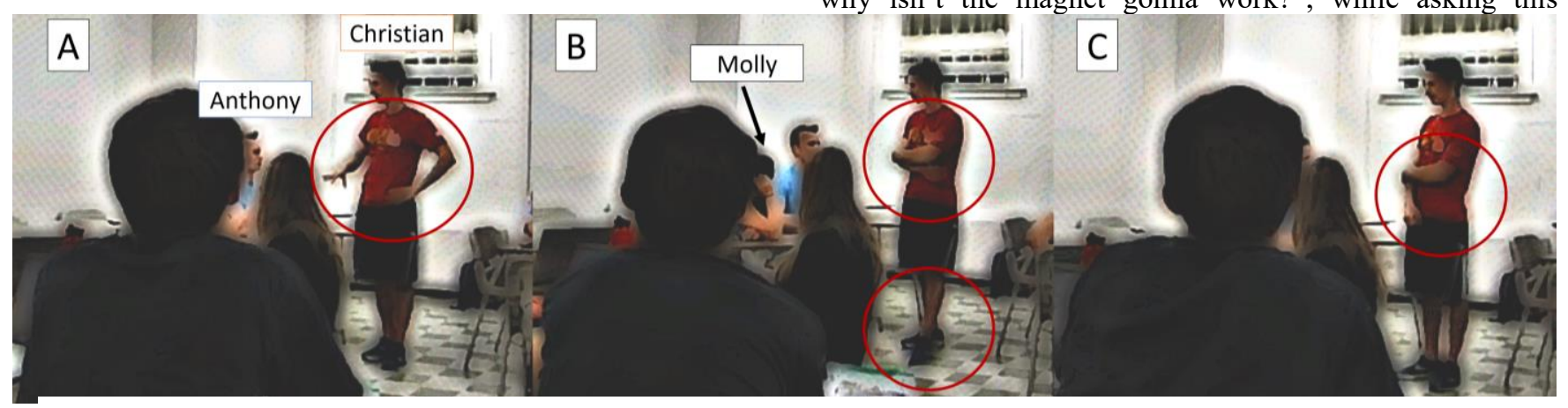

Fig. 1 Three moments from the roleplay where Christian uses body language to subtly block Anthony. 
question, LA-C takes his hand off of the hip closer to Anthony and extends his palm downward, pointing slightly at Molly (figure 1A). LA-C clearly directs the question at Molly and subtly uses his arms to block Anthony from cutting off Molly After asking the question, he returns his hand to his hip. Molly says she does not think the material is magnetic. LA-C suggests that Molly and Anthony look into whether or not the material is magnetic. LA-C's speech and actions indicate that he notices and responds to Anthony's problematic actions, sometimes through body language rather than words. Anthony and LA-C may or may not have explicit knowledge or awareness about how they are replicating and responding to problematic power dynamics, but the doing of those actions is evidence of embodied knowledge.

Anthony then suggests a new idea, that the team use a claw with 5 serial motors to pick up the material. While explaining the claw, Anthony draws a picture; LA-C bends down and looks at the picture. Noticing this attention, Anthony asks LA-C what he thinks; LA-C replies that the claw seems like a good idea, but asks Molly for her opinion. Again, LA-C directs attention to Molly and uses his position as an authority to make space for Molly's voice. Molly says she doesn't think they need so many serial motors. LA-C is quick to agree, using his power as an authority to validate Molly's ideas in front of Anthony; he supports her stance, giving it more power.

Anthony still pushes back against Molly's stance, arguing that five motors increases precision. LA-C asks Anthony what kind of precision is needed and crosses his arms over his chest (figure 1B). Anthony rambles about how extra precision would help and then launches into a story about how his friend who took the course last year used a claw and it almost worked. He then offers a new idea-a magnetic claw! He says that it combines the best of both his ideas. The audience (class) laughs at the idea of the combination. However, Anthony stays in characters and asks LA-C, not his teammate, if "we are in agreeance?" LA-C regains composure and says "Uh, no," then suggest that the team do some testing. While saying this, he slides his left foot out (the one closer to Molly), opening his body language to Molly. Anthony does not invite Molly to be in agreeance, but LA-C opens the question up to her.

Anthony interrupts LA-C and asks if they can buy a magnet. LA-C says that the lab has a magnet. Although Molly is correct that the debris is not magnetic, LA-C does not promote her idea; he may assume that testing will debunk the magnet idea.

Molly agrees to have the team test the idea; she says if it doesn't work they could try another option like a rack and pinion. Anthony asks what a rack and pinion is. LA-C asks Molly to draw an example. LA-C does not explain it to Anthony; he gives Molly the space to explain it, potentially leveraging her power and giving her space to contribute. While asking her, LA-C takes a small step in towards Molly, placing Anthony somewhat behind his back. At this moment, his body language is not open to Anthony and he is focusing on Molly. Again, LA-C's posture, speech, gesture, and gaze indicate that he is attending to the power dynamics between Molly and Anthony and tacitly using his body to respond. So, LA-C's responses display embodied knowledge of mitigating problematic power dynamics.

Molly sketches a rack and pinion for Anthony. While she is talking, LA-C has one arm across his chest and the other hanging down by his side (image $1 \mathrm{C}$ ). His feet are positioned in a V that is open towards Molly and closed off on Anthony's side. Anthony's stuttering and hedging may indicate that he's uncomfortable or flustered. While Anthony is talking, LA-C takes a small step towards Molly and says that the team should test both options. At this point, an Instructor calls an end to the roleplay.

\section{B. Class Discussion}

Following the roleplay, the instructor asks the class which instructor moves stood out to them during the roleplay. One LA points out that LA-C used the quiet student's name and created space for her to contribute, and noticed that the quiet student had tractionable ideas,. The observing LAs mention how LA-C interrupted Anthony's interruption of Molly and redirected the attention back to Molly. Another LA talks about how LA-C used subtle moves to include the quieter person in the discussion without labeling or calling out dynamics that might leave the relationship on rocky terms. So, after watching the roleplay, the observing LAs were able to notice the power dynamics between Molly and Anthony and comment on LA-C's instructional moves and their effects.

Instructor asks if the LAs who acted in the roleplay had any insights. Neither LA-C nor Molly comment. However, Anthony shares his perspective with the class. His expresses how LA-C's moves affected him as the overbearing student. He says,

You mentioned like when he interrupted my interruption. Um, I think one kind subtle thing he did was he stepped kind of in front of me a little bit. I feel like when I said something that was kind of escalating the conversation, he escalated it one further. And from there, if I do it one more time, it becomes super blatant and awkward on my part. And like from there, stay quiet without saying something like "Let her speak" do this again, and then you just seem like an ass in front of everyone. Like more than you already do.

Anthony did not break character when the rest of the class was laughing. Anthony did not simply act as the overbearing student; he became the overbearing student. As such, Anthony's goal was to have his ideas heard, even at Molly's expense. He goes through some lengths to return the conversation to his ideas; Anthony perceived his interruption of Molly as escalating the conversation. He comments on 
how LA-C paired his speech with subtle, physical moves to make it more difficult for Anthony to interrupt Molly again. Anthony saw LA-C making space for Molly and tried to take LA-C's attention back. He points out LA-C's small step (shown in Figure 1B) to the rest of the LAs and explains that LA-C's block put him in a position where if he were to interrupt again, he would come off very poorly. Anthony recognizes how LA-C's move changed his position in the roleplay.

As Anthony discusses how the moves affected his character in the roleplay, he does not take offense to LA-C's moves. Rather, he analyzes LA-C's step for the audience and explains how the move "worked."

\section{DISCUSSION}

Here we focus on what Anthony got out of the roleplay and shared with the whole class, emphasizing how his insights go beyond those of those of the LAs who observed the roleplay.

As shown above, LA-C makes both verbal and physical moves to stop Anthony's domination and open space for Molly to share her ideas. With the exception of one LA pointing out that LA-C made eye contact with Molly, however, the observing LAs focus entirely on LA-C's verbal moves, breaking down how LA-C's utterances gave Molly space to talk., So, the roleplay made LA-C's linguistic cues visible to the observing LAs.

By contrast, during the class discussion, Anthony calls attention to LA-C's subtle physical move of stepping toward Molly and how it restricted Anthony's available moves, leaving him with two options: stop interrupting Molly or look bad in front of his group. LA-C's step towards Molly limited the following moves which Anthony could make. We speculate that Anthony's embeddedness in the roleplay, his experience of being shut out of the interaction, afforded his insight into the metalinguistic nature and effects of LA-C's move. LA-C's literal step communicated to Anthony to take a metaphorical step back. So, his participation in the roleplay allowed him to see the coupling of linguistic, metalinguistic, and emotional qualities of the interaction in ways that the observing LAs did not.

In conclusion: As we expected from previous research on roleplays in pre-service teacher education and LA pedagogy courses, the roleplay helped the observing LAs notice and discuss LA-C's verbal moves. Our more novel point is that the LA playing one of the students had emotionally-charged embodied experiences that helped him articulate insights about LA-C's non-verbal moves and how they addressed the lopsided power dynamics between the overbearing and quiet students. Anthony shares this during the subsequent discussion, creating the opportunity for the entire class to benefit. Inspired in part by this classroom episode, we are engaging in design research around our pedagogy course to support LAs in expanding their ways of addressing power dynamics in collaborative design teams. We encourage LA pedagogy course instructors to draw their students' attention to non-verbal moves and the impact those carry, as exhibited in roleplays and in real classroom video. We also urge a greater focus, in future research on roleplays in teacher/LA pedagogy courses, on the affordances of playing the role of students.

\section{ACKNOWLEDGEMENTS}

We would like to thank Gina Quan and Emilia Tanu for help in seminar design and data collection. Erin Sohr and Brandon Johnson for their feedback on the argument and writing. This work is supported by NSF EEC \#1733649, as well as AIE and the UMD College of Engineering.
[1] V. Otero, S. Pollock, and N. Finkelstein, Am. J. Phys., vol. 78, no. 11, pp. 1218-1224, 2010.

[2] D. H. Palmer, Res. Sci. Educ., vol. 36, no. 4, pp. 337353, 2006.

[3] I. Mogra, Teach. Educ. Netw. J., vol. 4, no. 3, pp. 415, 2012.

[4] M. Gartmeier et al., Instr. Sci., vol. 43, no. 4, pp. 443-462, 2015.

[5] D. Loewenberg Ball and F. M. Forzani, J. Teach. Educ., vol. 60, no. 5, pp. 497-511, 2009.

[6] M. K. Cook, V. Korff, and J. S, presented at the 2016 Physics Education Research Conference Proceedings, 2016, pp. 80-83.
[7] E. D. Tanu, G. M. Quan, A. Gupta, and C. A. Turpen, in 2017 ASEE Annual Conference \& Exposition, Columbus, OH, 2017.

[8] G. M. Quan, C. A. Turpen, A. Gupta, and E. D. Tanu, "presented at the American Society for Engineering Education Annual Conference \& Exposition, Columbus, OH, 2017.

[9] M. Wilson, Psychon. B Rev., vol. 9, no. 4, pp. 625636, Dec. 2002.

[10] C. Goodwin, Discourse Soc., vol. 18, no. 1, pp. $53-$ 73, 2007. 